\title{
Antifungal activity of essential oil from Cinnamomum longepaniculatum leaves against three dermatophytes in vitro
}

\author{
Cui Tao ${ }^{1}$, Qin $\mathrm{Wei}^{2}$, Zhong-Qiong Yin ${ }^{1,2 *}$, Li-Jun Zhou ${ }^{2}$, Ren-Yong Jia ${ }^{1,2}$, Jiao Xu ${ }^{1}$, \\ Dong-Xia Shi ${ }^{1}$, Yi Zhou ${ }^{1}$, Yong-Hua $\mathrm{Du}^{2}$ and Yun-Xia Deng ${ }^{1}$ \\ ${ }^{1}$ College of Veterinary Medicine Sichuan Agricultural University, Ya-an, 625014, China. \\ ${ }^{2}$ Key Laboratory of Fermentation Resource and Application of Institutes of Higher Learning in Sichuan, Yibin College, \\ Yibin 644000, China.
}

Accepted 16 September, 2011

\begin{abstract}
The antifungal effects of essential oil from Cinnamomum longepaniculatum leaves were studied with special reference to minimal inhibitory concentration (MIC), minimal fungicidal concentration (MFC), time-kill studies and the mechanism of inhibition at ultrastructural level against Trichophyton mentagrophytes, Microsporum canis and Trichophyton gypseum. Its MICs against three important dermatophytes were $3.125,3.125$ and $3.125 \mathrm{ul} / \mathrm{ml}$, while its MFCs against the same were $3.125,3.125$ and $3.125 \mathrm{ul} / \mathrm{ml}$, respectively. All strains exposed to $1 \times \mathrm{MIC}$ showed a maximum decrease in fungal inoculum of less than $2 \log 10 \mathrm{CFU} / \mathrm{ml}$ within $12 \mathrm{~h}$, and all the strains exhibited no growth within $72 \mathrm{~h}$. Transmission electron microscope (TEM) of three important dermatophytes exposed to MIC levels of essential oil showed irreversible damage to cell wall, cell membrane and cellular organelles. The results are compared and with the data in literature. In conclusion, essential oil has significant antifungal activity in vivo, weakening the virulence of three dermatophytes and killing fungi by destroying the cell membrane and organelles.
\end{abstract}

Key words: Essential oils, antifungal activity, time-kill curve, transmitted electron microscopy (TEM).

\section{INTRODUCTION}

Cinnamomum longepaniculatum (Gamble) N. Chao, an endemic Lauraceae (Lauraceae) Cinnamomum plant species in China, has been listed as national key protected wild plant II level, which is mainly distributed in Sichuan Yibin, Hubei, Hunan, Shaanxi, Yunnan, Jiangxi, Guangxi, Guangdong and other places (Li et al., 1993; Tao et al., 2002). The chemical constituents of essential oils from $C$. longepaniculatum leaves found in Yibin of Sichuan Province in China have been studied by many researchers. Luo et al. (2001) analyzed the composition of the essential oils of the province. 26 main compounds were identified including 1,8-cineole (58.55\%), abietinol, Sabinene etc. 1,8-cineole is used as food additives, often employed by the industry in drug formulations, as a percutaneous penetration enhancer and for its decongestant and pharmaceutical anti-tussive effects; it is used in aromatherapy as skin stimulant in the form of skin baths (Helander et al., 1998; Laude et al., 1994; Levison et al., 1994; Macht, 1938; Williams and Barry, 1991). Also, it is considered useful for the treatment of bronchitis, sinusitis and rheumatism (McGilevery and Reed, 1993). Wei et al. (2006, 2009) have demonstrated that essential oils from $C$. longepaniculatum leaves have antibacterial and antifungi toxic properties. But, the potential activities of the essential oils from $C$. longepaniculatum leaves against dermatophytes have not

*Corresponding author. E-mail: yinzhongq@163.com. Tel/fax: +868352885614. 
yet been evaluated. This study was undertaken to know the morphological changes of three important dermatophytes (Trichophyton mentagrophytes, Microsporum canis and Trichophyton gypseum) under restraint with essential oil; specifically, to find out the antimicrobial activity of essential oil from the leaves of $C$. longepaniculatum in Yibin. The results may be promising in controlling fungal growth and knowing the mode of action of antifungal components of $C$. longepaniculatum.

\section{EXPERIMENTS}

\section{Materials}

Essential oil, extracted from the leaf of C. Iongepaniculatum (Gamble) N. Chao using steam distillation, was purchased from a company in Yibin of China. It was kept at $4^{\circ} \mathrm{C}$ until it was used.

\section{Microorganisms}

The three dermatophytes used during the growth experiments are as follows: Trichophyton mentagrophytes, Microsporum canis, and Trichophyton gypseum, supplied by the Sichuan Animal Husbandry and Veterinary Institute, Sichuan, China. The samples of mycelium necessary for the in vitro experiments were taken from cultures grown in slants and kept on Sabouraud's agar (SDA). Spore suspensions were prepared and diluted in sterile Roswell Park Memorial Institute-1640 (RPMI-1640) broth to a concentration of approximately $10^{7} \mathrm{CFU} / \mathrm{ml}$. Spore population was counted using haemocytometer. Subsequent dilutions were made from theaforementioned suspensions, which were then used in the tests.

Minimal inhibitory (MIC) and minimal fungicidal (MFC) concentrations determinations

MIC of the samples was determined by the broth dilution method using RPMI-1640 broth as described previously (Espinel-Ingroff et al., 2002; Trilles et al., 2004). The media containing $100 \mu \mathrm{l} / \mathrm{ml}$ of essential oils were serially diluted twofold each to give concentrations of $100,50,25,12.56 .25,3.125,1.563,0.781$ and $0.391 \mu \mathrm{l} / \mathrm{ml}$. To the diluted solution, equal volume of RPMI-1640 media inoculated with three dermatophytes at a concentration of $2 \times 10^{4} \mathrm{CFU} / \mathrm{ml}$ was added and mixed well. The mixture was incubated at $27^{\circ} \mathrm{C}$ for one week to check the minimal concentration, at which growth of the fungi cells was fully inhibited. The least concentration showing no visible growth on sterile sabouraud's agar (SDA) by subculture was taken as MFC value. A similar experiment was carried out using DMSO instead of essential oils from $C$. longepaniculatum leaves as a control. Three replicates were used for each concentration and all experiments were repeated twice.

\section{Kill-curve studies}

The effects of essential oil exposure in relation to time and concentration on three dermatophytes were determined in RPMI1640 liquid medium. Conidial suspensions $\left(1 \times 10^{3}\right.$ to $\left.1 \times 10^{4} \mathrm{CFU} / \mathrm{ml}\right)$ were incubated in the presence of MIC concentrations of essential oil from C. longepaniculatum leaves $(3.125 \mu \mathrm{l} / \mathrm{ml})$. $312.5 \mu \mathrm{l}$ of essential oil at the dilution determined by MIC was added to $100 \mathrm{ml}$ of each spore suspension containing $1 \times 10^{3}$ to $1 \times 10^{4} \mathrm{CFU} / \mathrm{ml}$ and was then incubated at an ambient atmosphere at $27^{\circ} \mathrm{C}$ in an incubator shaker. Samples were taken after 0, 2, 4, 8, 10, 12, 24,
$36,48,60$ and $72 \mathrm{~h}$; and $0.1 \mathrm{ml}$ of aliquot of the conidial suspension was removed and diluted to obtain $10^{1}$ to $10^{3}$ dilutions. $1 \mathrm{ml}$ of aliquot was cultured on SDA plates and incubated in an ambient atmosphere at $27^{\circ} \mathrm{C}$ for one week and the total number of viable spores per $\mathrm{ml}$ was calculated. Kill-curves were constructed by plotting mean $\mathrm{lgCFU} / \mathrm{ml}$ against the time of exposure of conidia to essential oil from $C$. longepaniculatum leaves.

\section{Sample preparation for TEM}

The essential oil from $C$. longepaniculatum leaves was added to a culture medium and reached a final concentration of $3.125 \mu \mathrm{l} / \mathrm{ml}$ with optical density of $10^{6} \mathrm{CFU} / \mathrm{ml}$; then it was incubated on a shaker at $27^{\circ} \mathrm{C}$ for $24 \mathrm{~h}$. Mycelial samples were fixed with $2.5 \%$ glutaraldehyde in $0.1 \mathrm{M}$ cacodylate-buffer $(\mathrm{pH}=7.4)$ at $4^{\circ} \mathrm{C}$ overnight. They were washed three times, each time for $15 \mathrm{~min}$, in cacodylate-buffer. Specimens were then post-fixed for $2 \mathrm{~h}$ in $1 \%$ osmium tetroxide (OsO4) dissolved in cacodylate-buffer at room temperature and washed in cacodylate-buffer (three times for 15 min each). Samples were dehydrated in a graded series of ethanol $(40,60,75,80$, and $95 \%$, two times for $15 \mathrm{~min}$ each and two times for 30 min each in $100 \%$ ethanol). Epoxy resin (Epon618 ) was used to embed the post-fixed fungi samples for 12 to $16 \mathrm{~h}$ at $45^{\circ} \mathrm{C}$. Ultra thin section of the embedded samples was prepared by LKB-II Ultracut instrument and double stained with uranyl acetate and lead citrate. The samples were lyophilized and then examined by transmitted electron microscope on a Hitachi TEM1011 instrument. The optical density at $10^{4} \mathrm{CFU} / \mathrm{ml}$ was recorded to evaluate the growth of the fungi.

\section{RESULT AND DISCUSSION}

\section{MIC and MFC studies}

The MICs and MFCs of the essential oil against three dermatophytes estimated by the microdilution technique were equally $3.125 \mu \mathrm{l} / \mathrm{ml}$. It was considered that if essential oil once reached MIC concentration, it displayed fungicidal activity. The MICs and MFCs found for essential oil against pathogenic fungi plant were similar to the values of in vitro susceptibility reported in the literature (Wei et al., 2006).

\section{Kill-curve studies}

The effect of essential oil on the growth of three dermatophytes is illustrated in Figure 1. The results indicate that concentrations of $1 \times \mathrm{MIC}$ of essential oil had an inhibitory effect on the growth of these organisms. Essential oil exerted maximal killing within 6 to $8 \mathrm{~h}$ in all experiments with a concentration of $1 \times \mathrm{MIC}$. All strains exposed to $1 \times$ MIC showed a maximum decrease in fungal inoculum of less than $2 \log 10 \mathrm{CFU} / \mathrm{ml}$ within $12 \mathrm{~h}$ and all the strains exhibited no growth within $72 \mathrm{~h}$ (Figure 1). The changes in fungal inoculum of $M$. canis after exposure to an essential oil concentration of $1 \times$ MIC were comparable with those of T. mentagrophytes and T. gypseum (Figure 1). The results suggest a maximum killing ability against Microsporum canis at $1 \times$ MIC and that no further killing can be achieved against the other two strains at $1 \times$ MIC. 


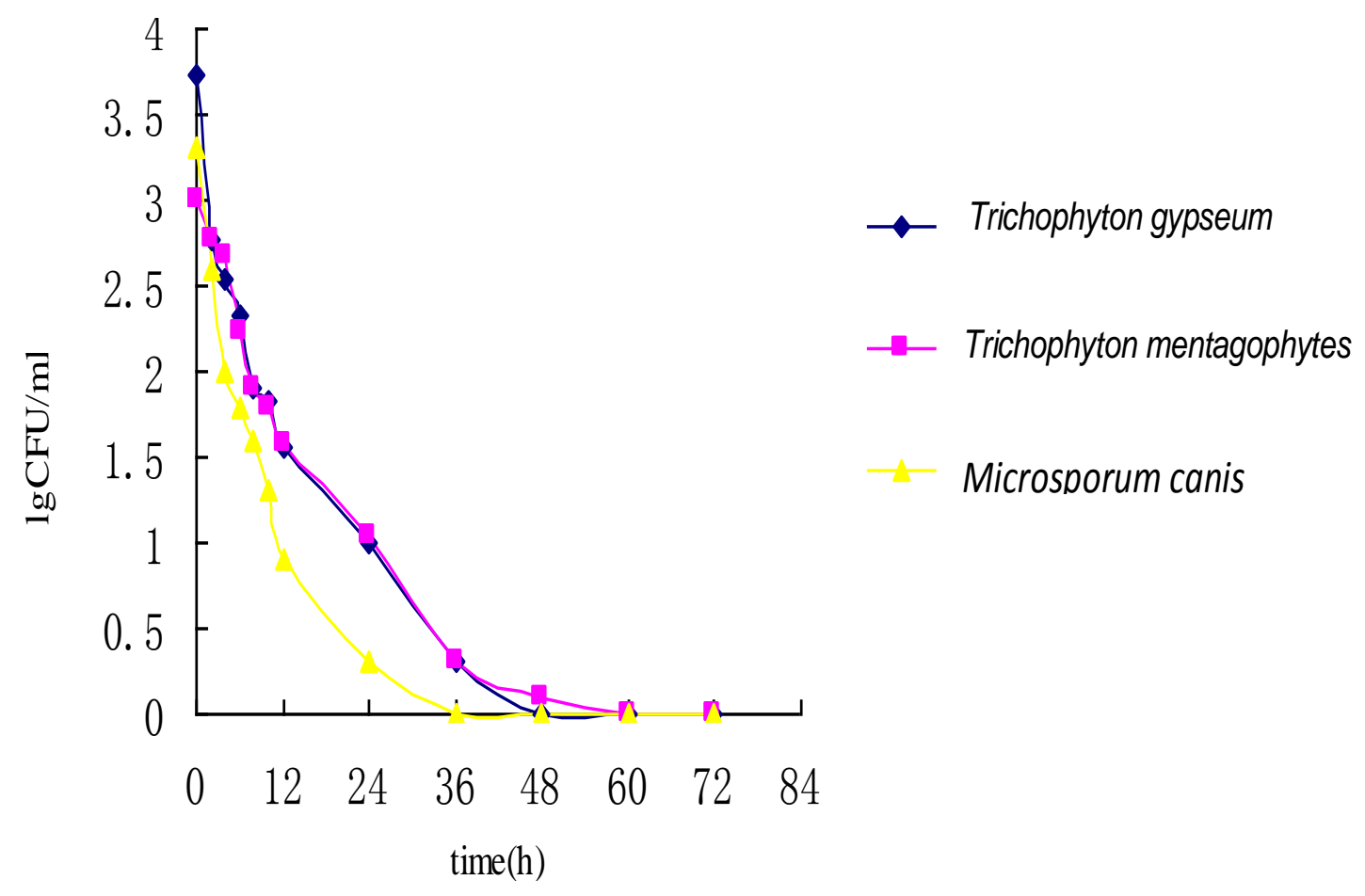

Figure 1. The time-kill cure of essential oil at MIC concentration from $C$. longepaniculatum leaves against three dermatophytes.

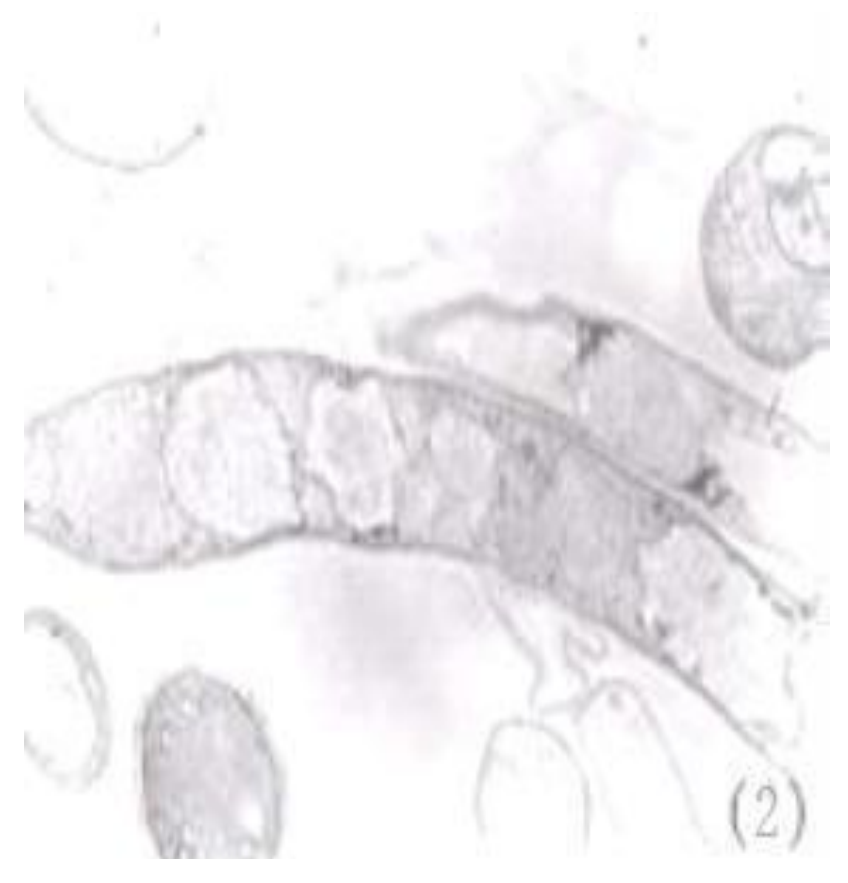

Figure 2. Ultrastructure of $T$. mentagrophytes were untreated with $1 \times \mathrm{MIC}$ essential oil with normal septum, endomembrane system, wall and organelles $(\mathrm{G} \times 8,000)$.

Our most striking finding was that starting essential oilconcentrations of $1 \times$ MIC were largely effective and significantly inhibited all isolates; whereas the residence time of essential oil in vitro brought about by declining sterilizing ability. The reduction of sterilizing ability may be due partly to volatile effective constituents. The present study suggests that essential oils concentration of MIC yielded an excellent fungal effect on three dermatophytes and might be sufficient to achieve fungal killing over a $72 \mathrm{~h}$ period.

\section{The result of TEM}

Scanning electron micrographs of three dermatophytes treated or untreated with $1 \times \mathrm{MIC}$ essential oil for $24 \mathrm{~h}$ are as follows:

1. Solvent controls samples (Figure 2): The ultrastructure of untreated T. mentagrophytes cell is shown in Figure 2. Mycelia were made up of long strands of hyphae, normally elongated with smooth walls where outer membrane, periplasm and cytoplasmic membrane could be seen.

2. The experimental group (Figure 3): T. mentagrophytes treated with essential oil are shown in (Figure 3). The fungal cells showed morphological changes; bleb-like structures, were observed. The ultrastructural changes included an alteration of the space between the cell wall and the plasma membrane, deformed cells, disorganization and depletion of membranous organelles and reduction 


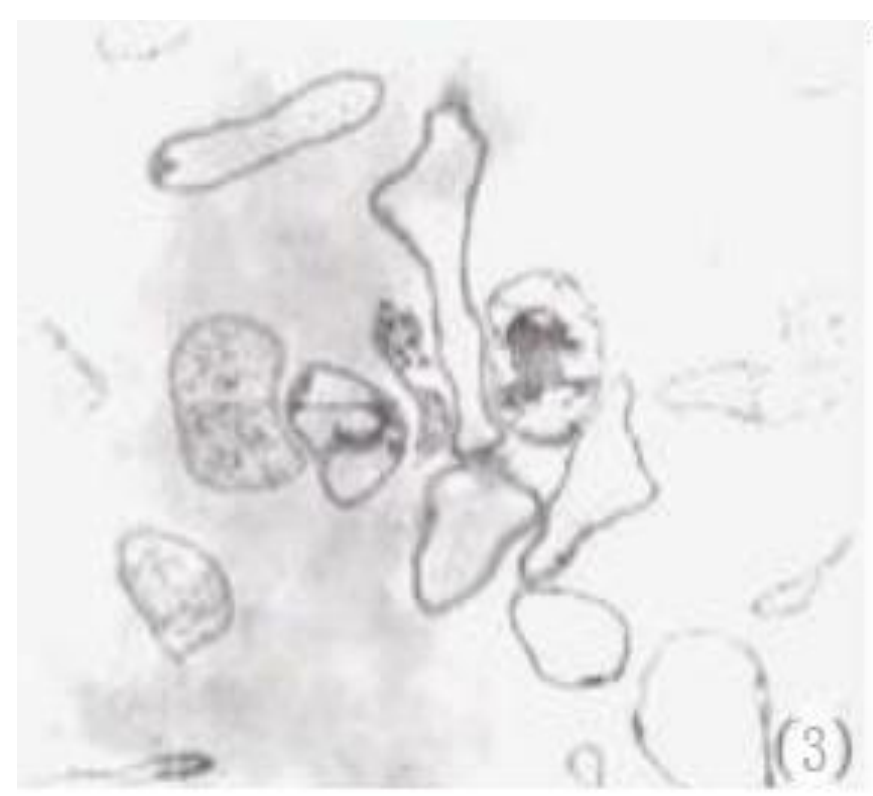

Figure 3. Ultrastructure of $T$. mentagrophytes were treated with $1 \times$ MIC essential oil with disorganization of cytoplasm and cytoplasm content, and losing its integrity. of outer wall $(\mathrm{G} \times 12,000)$.

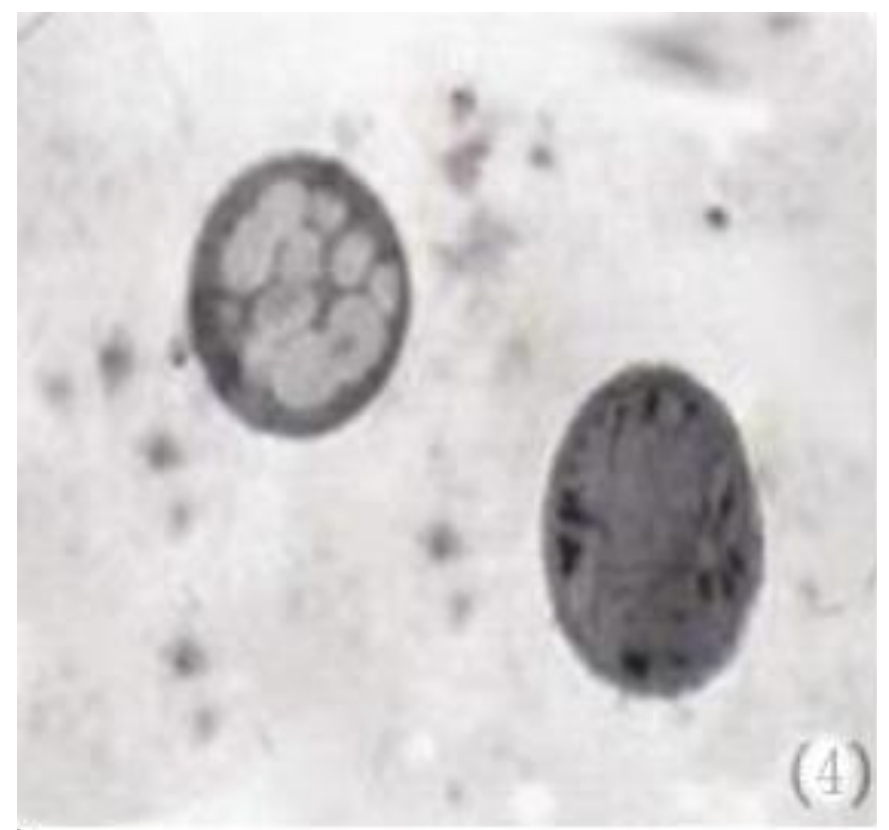

Figure 4. $M$. canis were homogenous. The cell wall, plasma membrane and intracellular organelles including mitochondria, vesicles, electron dense granules and nucleus had uniform and normal structures $(\mathrm{G} \times 12,000)$.

in cell size.

3. Solvent controls samples (Figure 4): M. canis maintained a normal morphology with membrane, periplasm, cytoplasmic membrane, nuclei, ribosomes and numerous granules of glycogen. The plasmalemma,

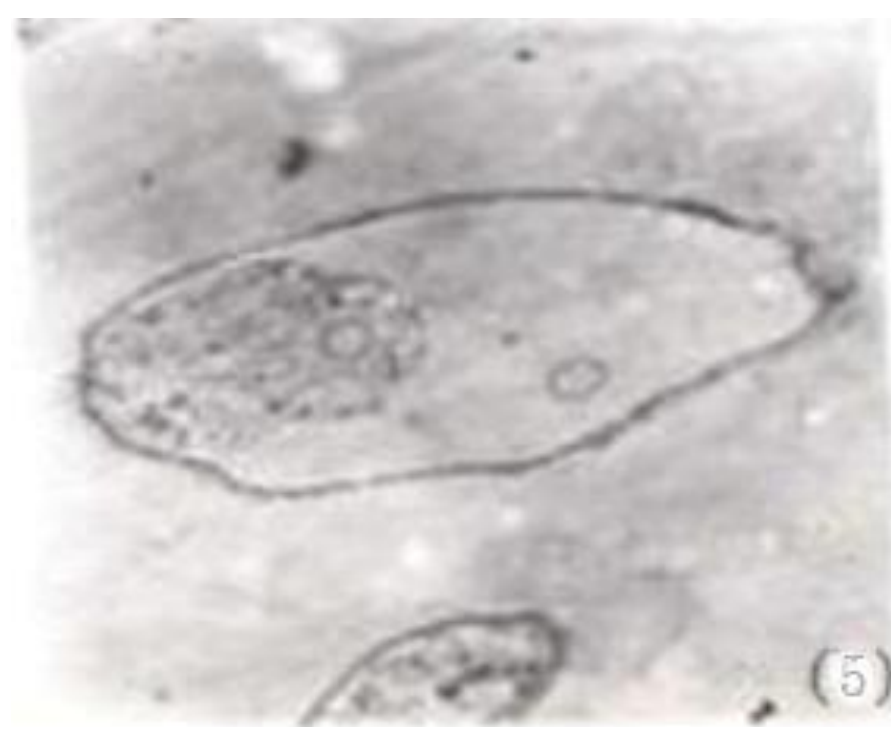

Figure 5. M. canis complete depression and disorganization signs including extensive destruction and lysis of hyphae membranous organelles such as nucleus and mitochondria, massive vacuolation of cytoplasm with vacuole fusion, complete autolysis and disorganization of hyphae cytoplasm $(G \times 15,000)$.

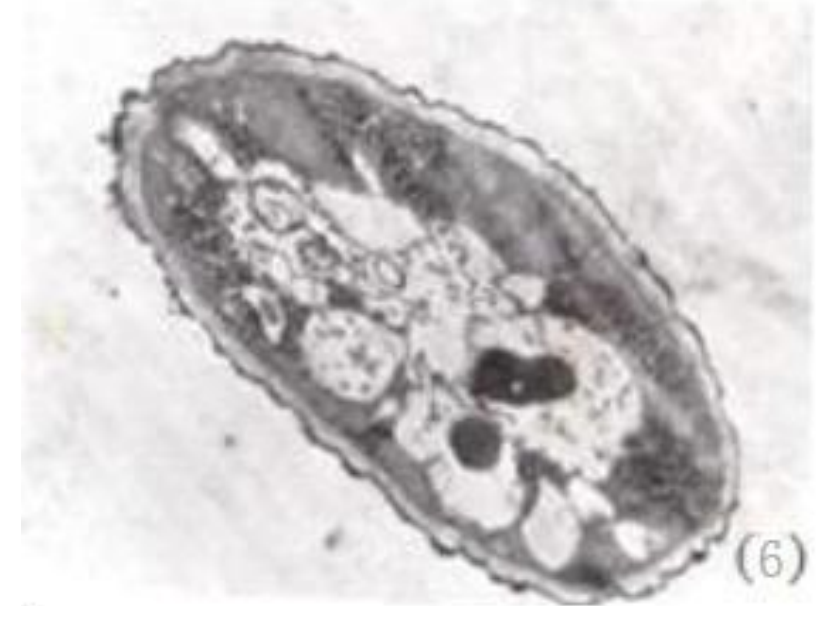

Figure 6. T. gypseum revealed typical eukaryotic cytoplasmic components including numerous ribosomes, mitochondria and vacuoles in the cytoplasm enclosed by an electron-transparent cell wall $(\mathrm{G} \times 6,000)$.

adherent to the cellular wall and the innersystem of endomembrane showed a normal morphology.

4. The experimental group (Figure 5): The outer membrane of $M$. canis rose up and separated from the wall, or it may even be stripped away and dispersed in the outside medium. Disorganization signs included extensive destruction and lysis of hyphae membranous organelles. 5. Solvent controls samples (Figure 6): TEM observation of untreated T. gypseum hyphae revealed typical eukaryotic cytoplasmic components including numerous ribosomes, mitochondria and vacuoles in the cytoplasm 


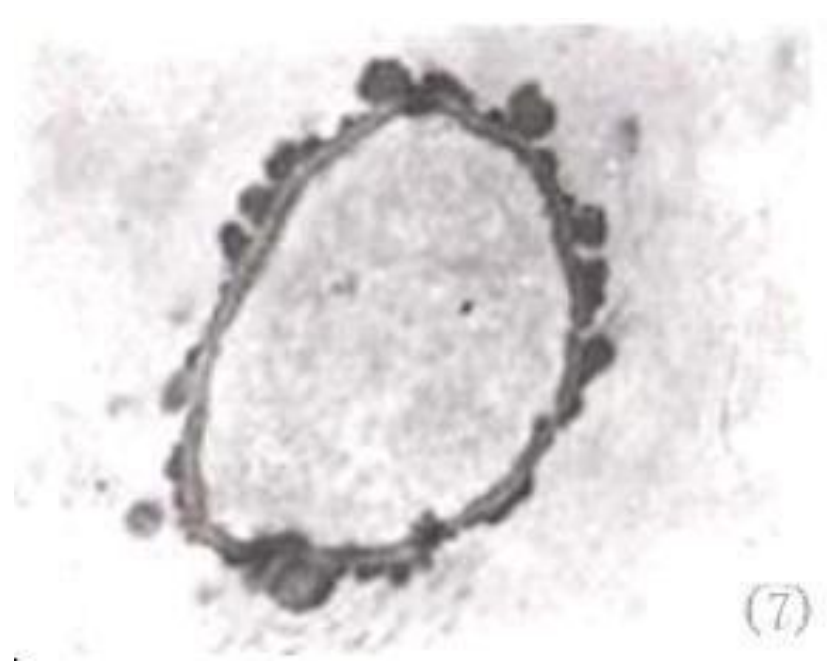

Figure 7. Normal T. gypseum with electron- transparent vacuoles, and deeply altered cells, with hardly recognizable organelles were visible $(\mathrm{G} \times 8,000)$.

antifungal activity of Chinese herbs, their mechanism of action is not well understood. Some literatures have reported (Ghahfarokhi et al., 2004; Jiang and Cao,1999; Moreira et al., 2005; Parka et al., 2009; Soylu et al., 2006) the mechanism of the antifungal activities of some Chinese herbs, such as damaging the integrity and continuity of fungal cell wall and cell membrane, causing cell swelling, necrotizing or disintegrating organelles, affecting its nucleic acid or lipid metabolism and so on. When treated with $1 \times$ MIC essential oil for $24 \mathrm{~h}, T$. mentagrophytes showed shrunk hyphe cell, dissolved or destroyed organelle and nucleus. Meanwhile, the cytoplasm of $M$. canis and T. gypseum was occupied by low electron-densed areas and generated large amounts of white space. The deleterious effect of the essential oil on the three dermatophytes may be the main reason for the highly hydrophobic components of essential oil, which may readily pass through the cellular membrane and change its permeability. This leads to organelles disintegration or collapse, decrease of electron density, formation of a cystic space, restrain on the growth of mycelia, formation and germination of sporules; and eventually the fungi decay and die.

\section{ACKNOWLEDGEMENTS}

The research was supported by Program for Changjiang Scholars and Innovative Research Team in University (PCSIRT0848), Sichuan Science and Technology Agency supporting project (2009FZ0090), City Technology Bureau of Yibin (200903019). The authors would like to thank the Sichuan Animal Husbandry and Veterinary Institute for supplying fungus.

\section{REFERENCES}

Espinel-Ingroff A, Fothergill A, Peter J, Rinaldi MG, Walsh TJ (2002).Testing Conditions for Determination of Minimum Fungicidal Concentrations of $\mathrm{New}$ and Established Antifungal Agents for Aspergillus Spp. NCCLS Collaborative Study . J. Clin. Microbiol. 40(9): 3204.

Ghahfarokhi MS, Goodarzia M, Abyaneh MR, Al-Tiraihic T (2004). Seyedipourd G. Morphological evidences for onion-induced growth inhibition of Trichophyton rubrum and Trichophyton mentagrophytes. Fitoterapia 75(7-8): 645-655.

Helander IM, Alakomi HL, Latva-Kala K, Mattila-Sandholm T, Pol I, Smid EJ (1998).Characterization of the action of selected essential oil components on Gram-negative bacteria. J. Agric. Food Chem. 46: 3590-3595.

Jiang T, Cao Y (1999). Study on Antlfungal Action of 22 effective Compoments of Chinese Herbs and Application of new Preparations. Chin. J. Dermatol. 32(005):316-318.

Laude EA, Morice AH, Grattan TJ (1994). The antitussive effects of menthol, camphor and cineole in conscious guinea-pigs. Pulm. Pharmacol. 7:179-184.

Levison KK, Takayama K, Okabe K, Nagai T (1994). Formulation optimization of indomethacin gels containing a combination of three kinds of cyclic monoterpenes as percutaneous penetration enhancers. Pharm. Pharmacol. 83:1367-1372.

Li YJ, Li BL, Zeng HT,Lu BY, Zhu LF (1993). The chemical types on Cinnamoraum longepanlculatum (Gamble)N. Cho ex H. W .Li in Hunan Province. J. Plant Resour. Environ. 2(3):7-11.

Luo ZJ, Li WY, Wei Q (2001). The future development of essential oil from Cinnamomum longepaniculatum of Yibin. J. Sichuan Norm. Univ. 24(3): 317-319.

Macht $D$ (1938). The absorption of drugs and poisons through the skin and mucous membranes. Am. Med. Assoc. 110:409-414.

McGilevery C, Reed J (1993). Aroma therapy. Ultimate Editions, Lond.

Moreira MR, Ponce AG, Del-Valle CE (2005). Inhibitory Parameters of Essential Oils to Reduce a Foodborne Pathogen. LWT-Food Sci. Technol. 38(5):565-570.

Parka MJ, Gwaka KS, Yangb I, Kimc KW, Jeung EB, Change JW, Choia IG (2009). Effect of citral, eugenol, nerolidol and a-terpineol on the ultrastructural changes of Trichophyton mentagrophytes. Fitoterapia 80(5):290-296.

Soylu EM, Soylu S, Kurt S (2006). Antimicrobial activities of the essential oils of various plants against tomato late blight disease agent Phytophthora infestans. Mycopathologia 161(2):119-128.

Tao GF, Ding JK, Sun HD (2002). The Chemical Constituents of the Essential Oil from Leaves of Cinnamomum longepaniculatum in Hubei, China. J. Wuhan Bot. Res., 20(1): 75-77.

Trilles L,Fernandez-Torres B, Santos,Wanke B,Guarro J (2004). In vitro Antifungal Susceptibility of Cryptococcus Gattii. J. Clin. Microbial., 42(10): 4815.

Wei Q, Li Q, Luo Y (2006). Antifungal activity of leaf essential oil from Cinnamomum longepaniculatum (Gamble) N. Chao. Chinese J. Oil Crop Sci., 28(001): 63-66.

Wei Q, Zhou YK, Zhou NJ, Yin LG, Zhang P (2009). Inhibitive Activity of Cinnamomum Oil against Bacteria. Chinese J. Trop. Agric.

Williams AC, Barry BW (1991).Terpenes and the lipid-proteinpartitioning theory of skin penetration enhancement. Pharm. Res. 8:17-24. 